\title{
Particle induced nuclear reaction calculations of Boron target nuclei
}

\author{
Eyyup Tel ${ }^{1, *}$, Muhittin Sahan ${ }^{1}$, Ismail Hakki Sarpün ${ }^{2}$, Yusuf Kavun ${ }^{3}$, Ali Armagan Gök ${ }^{1}$, Meltem Poyraz ${ }^{1}$
}

${ }^{1}$ Osmaniye Korkut Ata University, Department of Physics, Osmaniye, Turkey
${ }^{2}$ Afyon Kocatepe University, Physics Department, Afyonkarahisar, Turkey
${ }^{3}$ Manisa Celal Bayar University, Department of Physics, Manisa, Turkey

\begin{abstract}
Boron is usable element in many areas such as health, industry and energy. Especially, Boron neutron capture therapy (BNCT) is one of the medical applications. Boron target is irradiated with low energy thermal neutrons and at the end of reactions alpha particles occur. After this process recoiling lithium-7 nuclei is composed. In this study, charge particle induced nuclear reactions calculations of Boron target nuclei were investigated in the incident proton and alpha energy range of 5-50 MeV. The excitation functions for ${ }^{10} \mathrm{~B}$ target nuclei reactions have been calculated by using PCROSS Programming code. The semi-empirical calculations for $(p, \alpha)$ reactions have been done by using cross section formula with new coefficient obtained by $\mathrm{Tel}$ et al. The calculated results were compared with the experimental data from the literature.
\end{abstract}

\section{Introduction}

Boron found wide spread in the rocks and water on the surface of the earth is an important element and is often underutilized, trace mineral naturally present in certain foods. Boron is used effectively in medical treatment. It is preferred because it gives effective successful results in the treatment of cancer. In order to be successful, a sufficient amount of ${ }^{10} \mathrm{~B}$ must be selectively delivered to all tumor cells and enough thermal neutrons must be absorbed to cause lethal damage from the ${ }^{10} \mathrm{~B}(\mathrm{n}, \alpha)^{7} \mathrm{Li}$ capture reactions [1-5]. After the absorption of the thermal neutron, two product nuclei (He and $\mathrm{Li}$ ) occurs. Their ranges in tissue are as short as the diameter of a cell nucleus and whose LET (Linear Energy Transfer) values are very high. Therefore, energy is released in the tumor cell which is killed with high probability because of the high LET owing to the short absorption ranges so that neighboring cells are not damaged [1]. In this study, particle induced nuclear reactions calculations of boron target nuclei have been investigated in the incident proton energy range of $1-50 \mathrm{MeV}$. The excitation functions for ${ }^{10} \mathrm{~B}$ target nuclei reactions $(p, \alpha),(p, n),(p, p)$ have been calculated using the semiempirical formula.

\section{Method}

Cline [6], Ribansky [7] and Griffin [8] uses the PCROSS code that is unified model based on the solution of the master equation in the form proposed.
The empirical cross section formula is including proton inelastic cross section and Coulomb effects of reactions induced by proton can be expressed suggested in many studies [9-26] as follows:

$$
\sigma_{(p, \alpha)}=C \sigma_{p-n e} \sigma_{C o u l} \exp (a s)
$$

Where $\sigma_{p-n e}$ and $\sigma_{\text {Coul }}$ (in unit of $\mathrm{mb}$ ) are the proton non-elastic and Coulomb effect cross sections, respectively [9]. The coefficients $C$ and $a$ have been determined from only empirical formulae. $\mathrm{Z}$ is the proton number of target nuclei.

\section{Results and Discussions}

In this study, Particle Induced Nuclear Reactions Calculations of Boron Target Nuclei have been investigated in the incident proton energy range of $1-$ $50 \mathrm{MeV}$. The $(p, \alpha),(p, n)$ and $(p, p)$ reactions have been calculated via the semi-empirical formula for the excitation functions of ${ }^{10} \mathrm{~B}$ target nuclei.

Full exciton model calculations have been done with PCROSS code [27] that used the initial exciton number as $n_{o}=1$ of 1 neutron and 0 hole [10-23]. Theoretical calculations of ${ }^{10} \mathrm{~B}(\mathrm{p}, \alpha)$ equilibrium and pre-equilibrium reactions are compatible with each other as seen in Fig. 1.

Equilibrium and pre-equilibrium calculations are tended to increase up to $20 \mathrm{MeV}$ but then tend to decrease in harmony. As seen in Fig. 2, ${ }^{10} \mathrm{~B}(\mathrm{p}, \mathrm{n})$ reactions calculations shows unstable increases and

\footnotetext{
*Corresponding author: eyuptel@osmaniye.edu.tr
} 
decreases after in the neighborhood of $43 \mathrm{MeV}$ the pre-equilibrium.

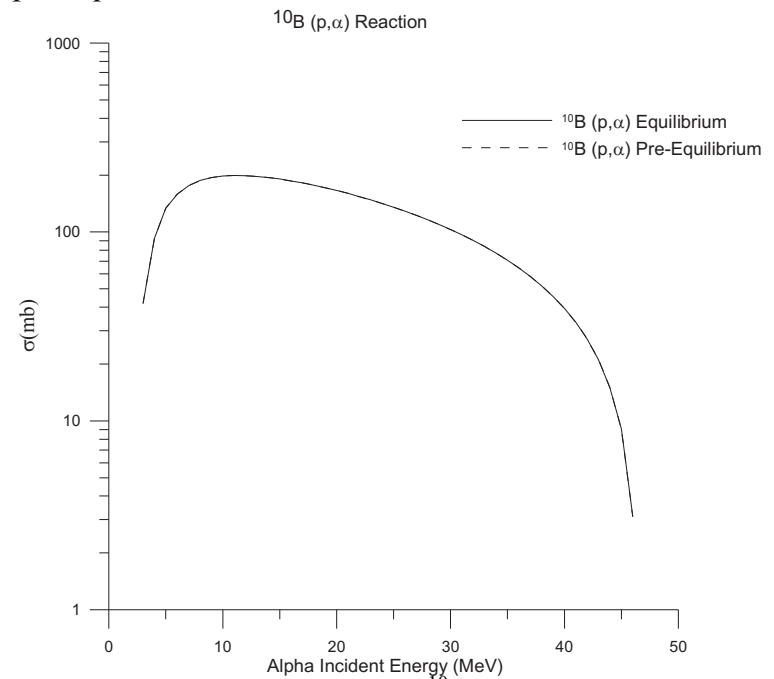

Fig. 1. Excitation function of ${ }^{10} \mathrm{~B}(\mathrm{p}, \alpha)$ reactions incident proton energy 1-50 MeV.

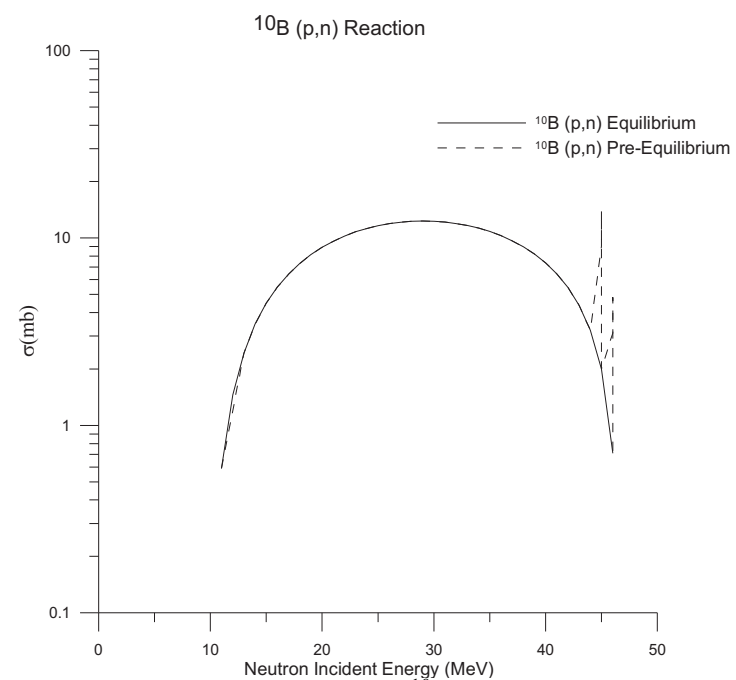

Fig. 2. Excitation function of ${ }^{10} \mathrm{~B}(\mathrm{p}, \mathrm{n})$ reactions incident proton energy 1-50 MeV.

In Fig. $3,{ }^{10} \mathrm{~B}(\mathrm{p}, \mathrm{p})$ reactions calculations are starting to occur around $5 \mathrm{MeV}$ and decreasing to until around $46 \mathrm{MeV}$.

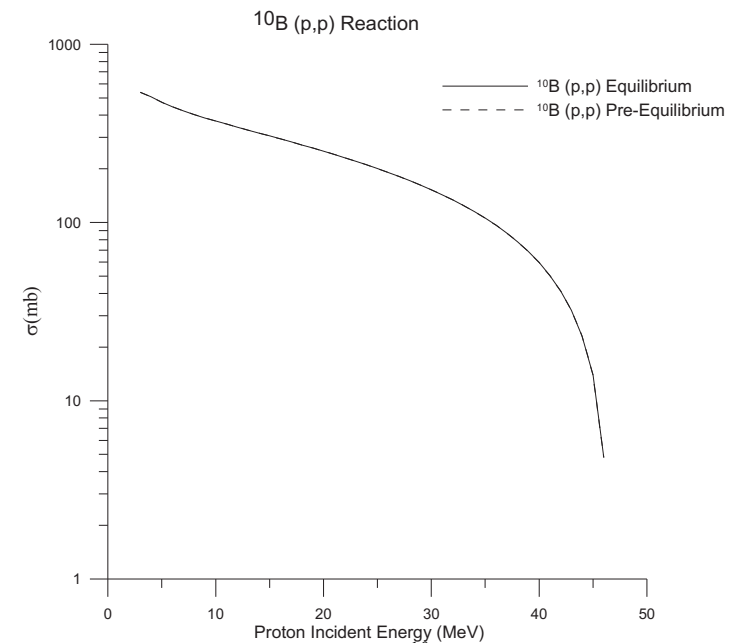

Fig. 3. Excitation function of ${ }^{10} \mathrm{~B}(\mathrm{p}, \mathrm{p})$ reactions incident proton energy 1-50 MeV.

\section{Acknowledgment}

The study was supported by Osmaniye Korkut Ata University (OKU) Science Research Projects Coordination Unit with the grant number: OKÜBAP2017-PT3-022

\section{References}

1. R.F. Barth, J.A. Coderre, M.G. Vicente, T.E. Blue, Clin Cancer Res 2005, 11: 3987-4002.

2. V.Y. Butko, X. Chi, D.V. Lang, and A.P. Ramirez, Appl. Phys. Lett. https://doi.org/10.1063/1.163173683, 4773 (2003).

3. H. Klauk, M. Halik, U. Zschieschang, G. Schmid, W. Radlik, and W. Weber, J. Appl. Phys. https://doi.org/10.1063/1.151182692, 5259 (2002)

4. H. Tada, H. Touda, M. Takada, and K. Matsushige, Appl. Phys. Lett. https://doi.org/10.1063/1.12561476, 873 (2000)

5. R.J. Harris, W.B. Shuler, M. Eckhause, R.T. Siegel, R.E. Welsh, Phys. Rev. Lett. 20, 505 (1968)

6. C.K. Cline, M. Blann: Nucl. Phys. A 172225 (1971)

7. I. Ribansky et al.: Nucl. Phys. A 205545 (1973)

8. J.J. Griffin, Phys.Rev. Lett. 17478 (1966)

9. E. Tel, A. Aydın, E.G. Aydın, A. Kaplan, O. Yavas, I.A. Reyhancan, PRAMANA Indian Academy of Sciences 74, 6, 931 (2010)

10. M. Sahan, E. Tel, H. Sahan, A. Kara, A. Aydin, A. Kaplan, I.H. Sarpun, B. Demir, S. Akca, E. Yildiz, J Fusion Energ 34, 493 (2015).

11. J.M. Akkermans et al.: Phys. Rev. C 22 73. (1980)

12. M. Belgaid, M. Asghar, Appl. Radiat. Isot. 491497 (1998)

13. E. Tel, H.M. Sahin, A. Kaplan, A. Aydin, T. Altinok, Ann. Nucl. Energy 35 (2) 220 (2007)

14. M. Yiğit, E. Tel and I.H. Sarpün, Nuclear Instruments and Methods in Physics Research A 385, 59 (2016)

15. E. Tel, M. Yiğit, G. Tanır, J. Fusion Energ. 31, 184 (2012)

16. E. Tel, M. Yiğit, G. Tanır, J. Fusion Energ. 32, 273 (2013)

17. M. Yiğit and E. Tel, Annals of Nuclear Energy 69, 44 (2014)

18. E. Tel, S. Akca, A. Kara, M. Yiğit and A. Aydın, J. Fusion Energ. 32, 531 (2013)

19. H. Şahan, E. Tel, M. Yiğit, J. Fusion Energ. 34, 16 (2015)

20. M. Yiğit and E. Tel. Nuclear Engineering and Design 293, 97 (2015)

21. M. Yiğit and E. Tel, J. Fusion Energ. 32, 442 (2013)

22. M. Yiğit, J. Fusion Energ. 34, 140 (2015)

23. M. Yiğit and E. Tel, Journal of Radioanalytical and Nuclear Chemistry 306, 203 (2015).

24. A. Kaplan, J. Fusion Energ. 32, 382 (2013).

25. A. Aydin, I.H. Sarpun, A. Kaplan, Phys. Atom Nucl. 77, 321 (2014).

26. A. Aydin, H. Pekdogan, A. Kaplan, I.H. Sarpun, E. Tel, B. Demir, J. Fusion Energ. 34, 1105 (2015).

27. R. Capote et al., Final Report on Research Contract 5472/RB, INDC(CUB)-004 (Higher Institute of Nuclear Science and Technology, Cuba). Translated by the IAEA on March 1991 (PCROSS program code) (1991). 